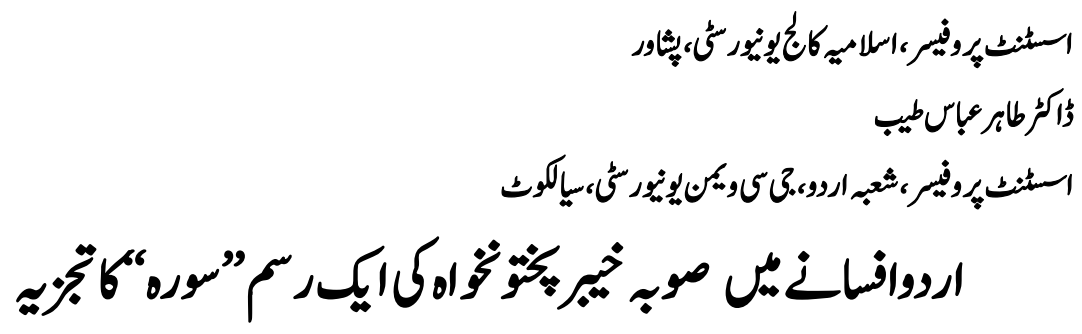

Dr. Anwar Ali

Assistant Professor, Islamia College University, Peshwar.

Dr. Tahir Abbas Taib

Assistant Professor, Department of Urdu, Govt. College Women University of Sialkot.

\title{
Ritual of "Surah" in KPK Urdu Fiction: An Analysis
}

There are numerous attributes in Pakhtunwali which shows the enlightened mind set of Pathans but it has its demerits as well. Pushtoons themselves don't approve of certain customs that they have been adhered to from ages. One of the bad customs in Pakhtoonwali is Swara. It is a statute of Pathans' national and social constitution which is still in vogue in some remote and backward areas. It says that when a member of a pushtoon's family is killed by an individual of another family and when both the families agree to bury the hatchet through arbitration of an impartial third party in order to stop further bloodshed, then Swara comes handy. And as a result, a maid of the murderer family is married off to the member of the bereaved family as compensation for the loss. Beside other bad practice, this too has been highlighted in Urdu fictions to convey the message that no one has the right to play with the lives of innocent individuals and that in case of mishap, only the culprit should bear the brunt. This treatise aims at showing the Pashtun an enlightened path and will prove to be milestone in pashtoon's culture.

Key Words: Pakhtunwali, Swara, customs, statute of Pathans' national and social constitution Vrdu fictions, aspects \&'. Social Awareness, Pashtoon's culture. 


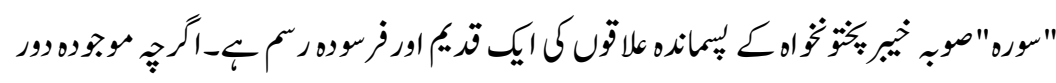

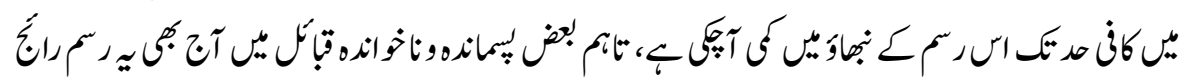

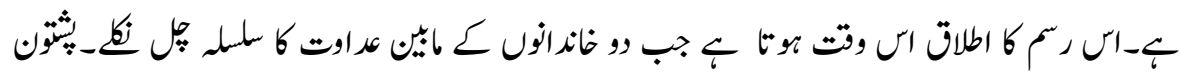

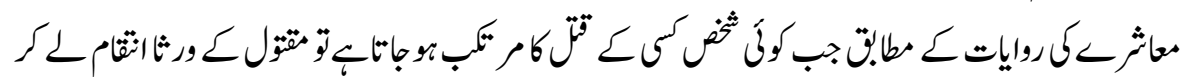

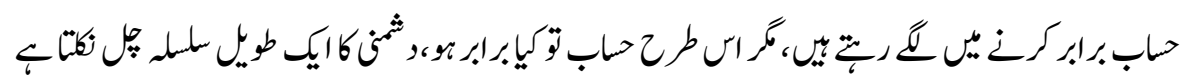

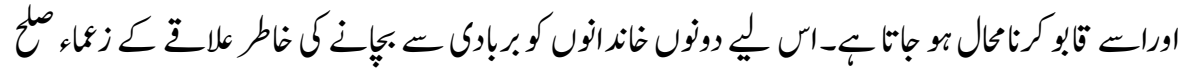

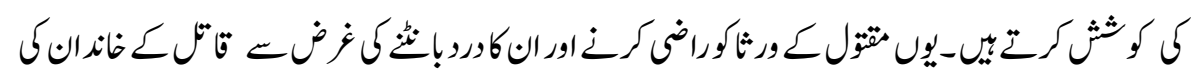

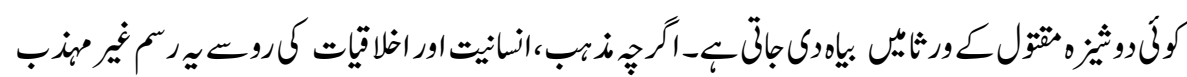

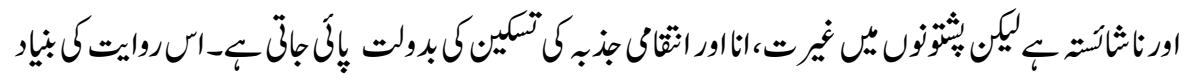

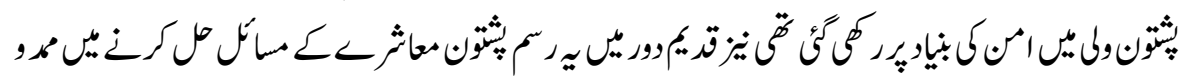

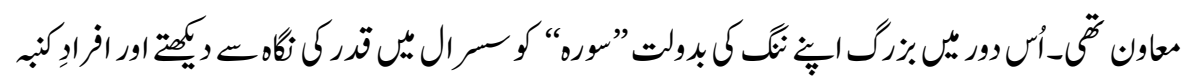

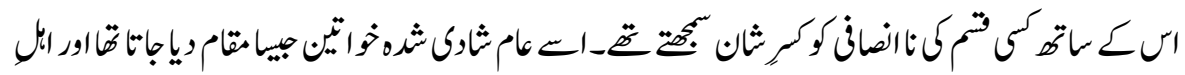

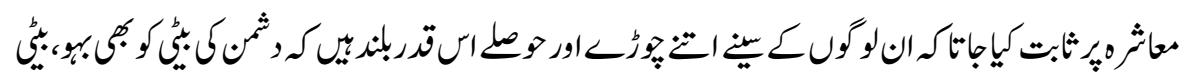

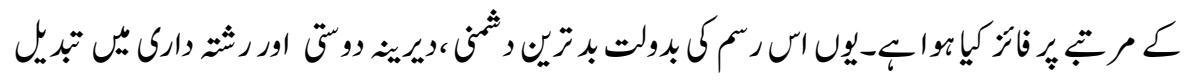

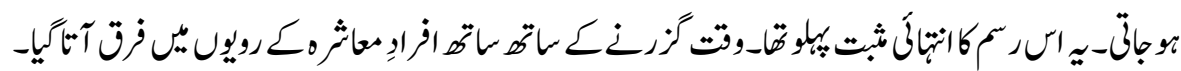

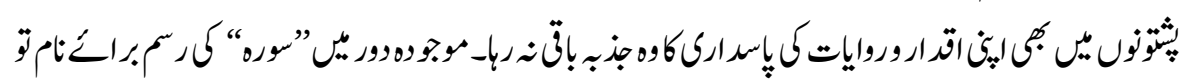

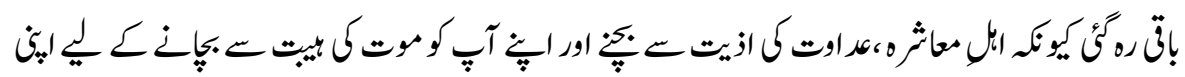

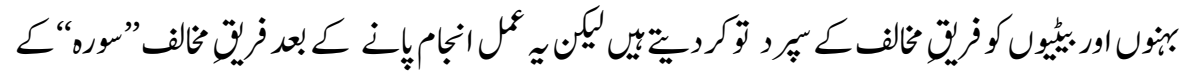

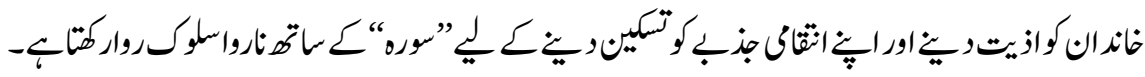

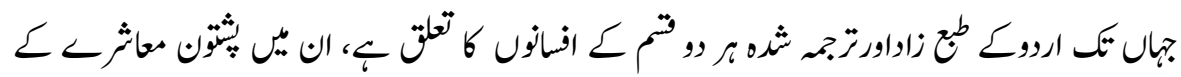

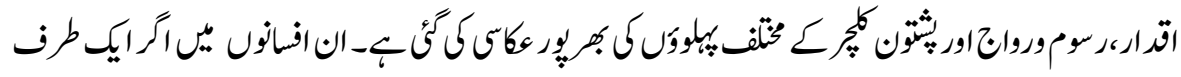

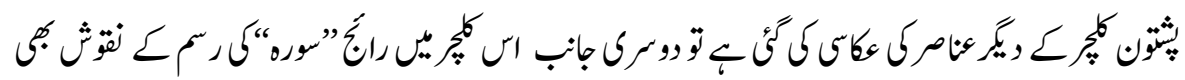

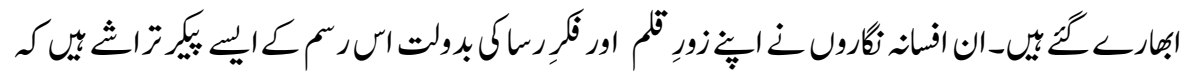




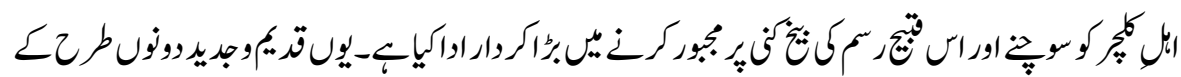

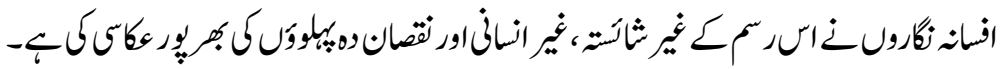

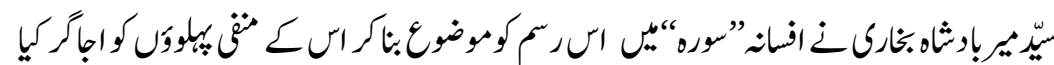

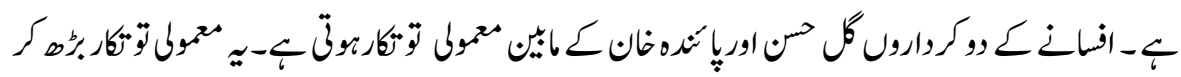

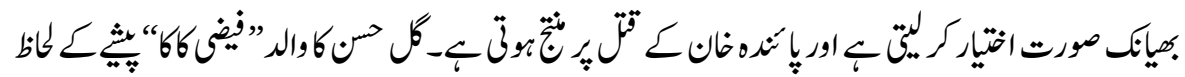

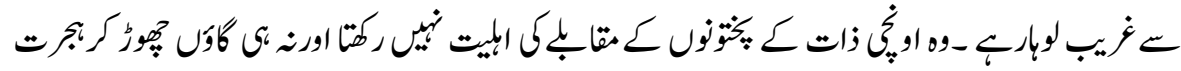

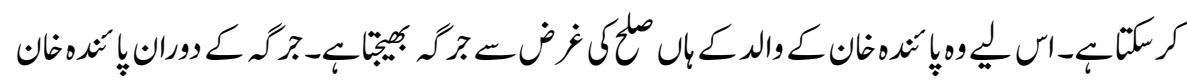

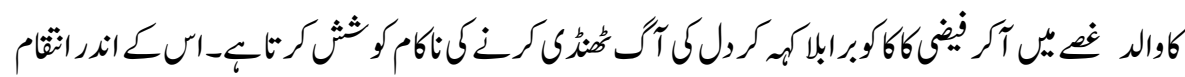

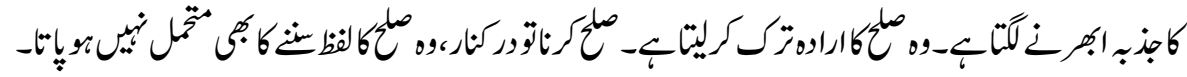

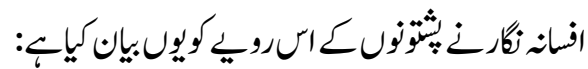

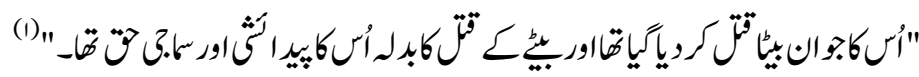

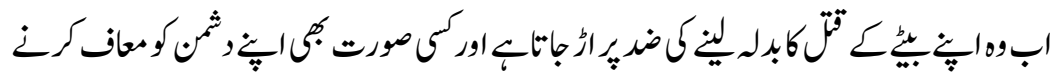

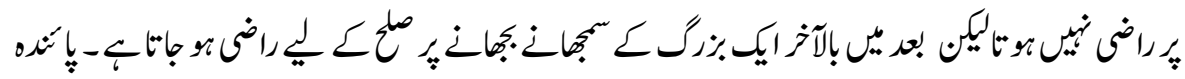

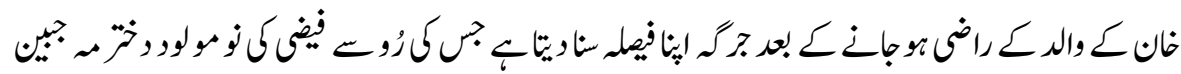

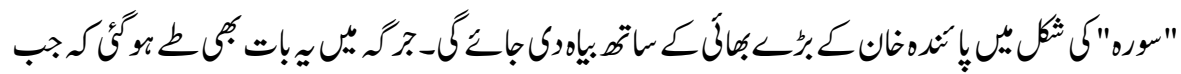

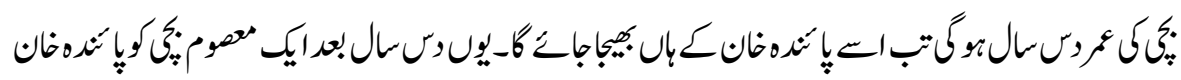

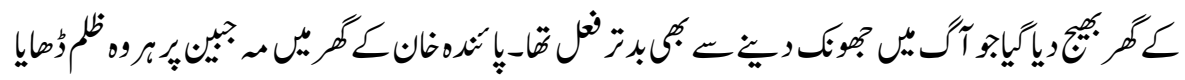

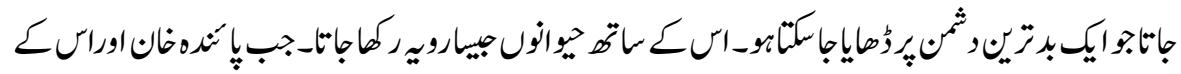

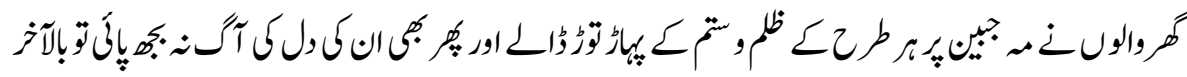

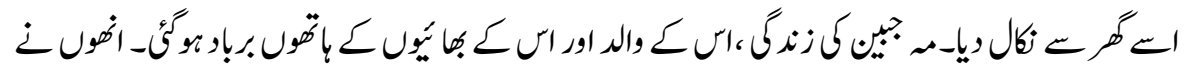

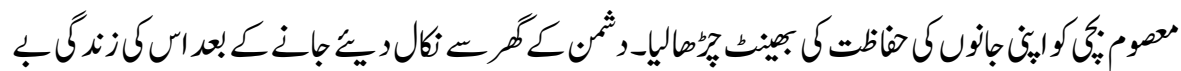

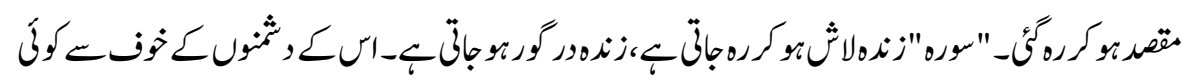

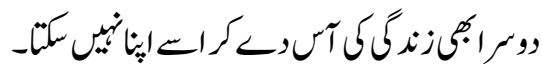




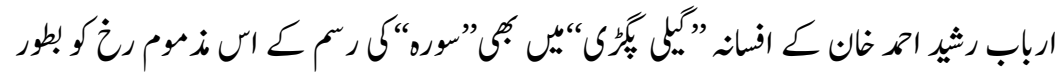

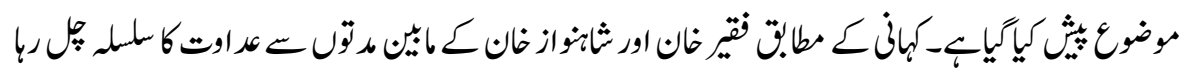

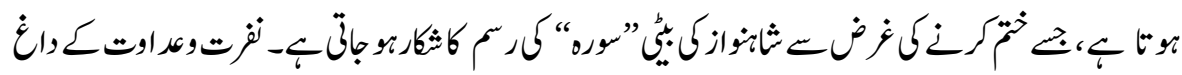

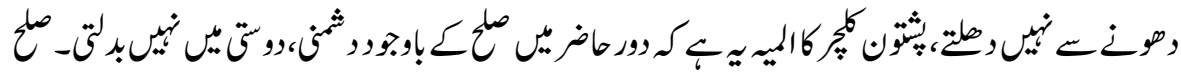

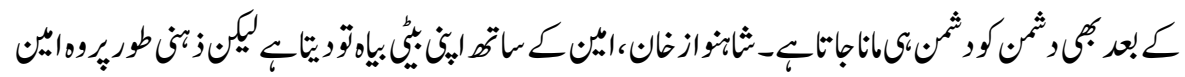

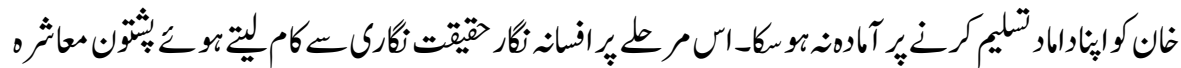

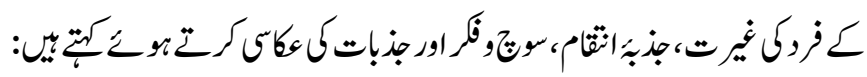

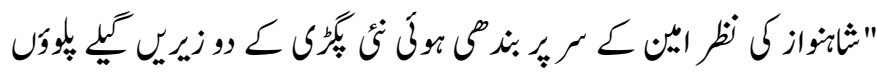

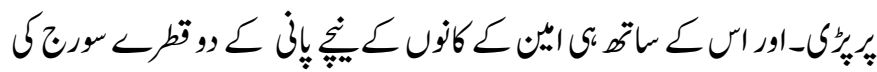

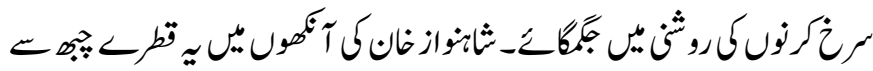

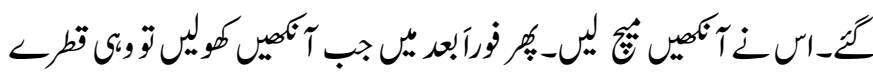

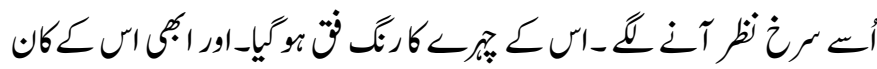

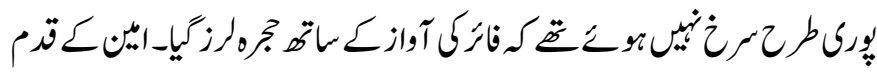

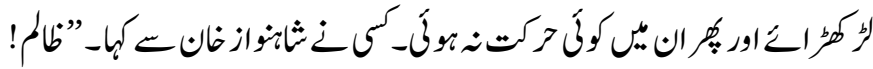

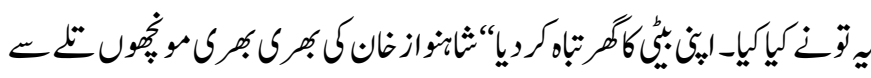

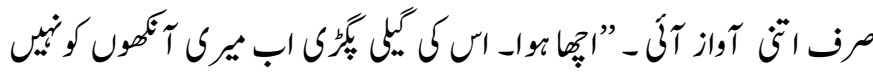

$$
\text { (r)" }
$$

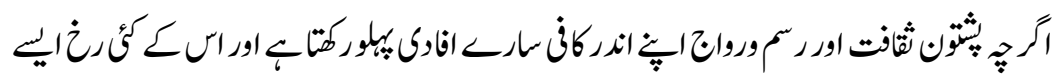

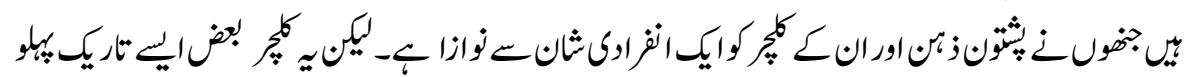

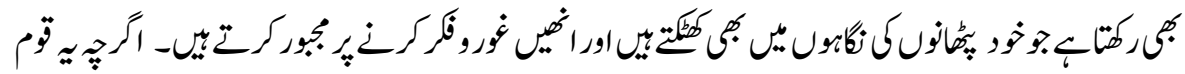

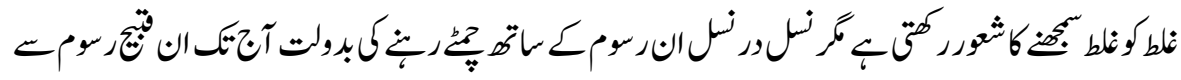

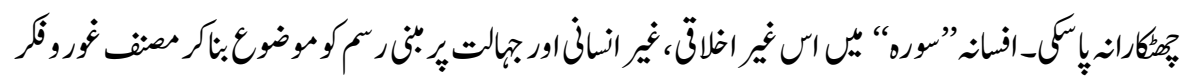

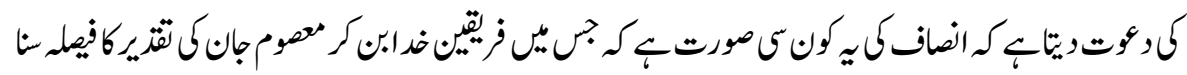




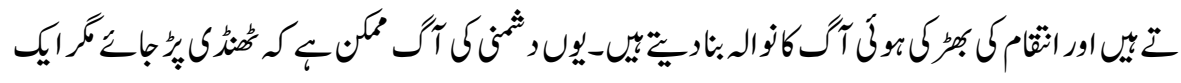

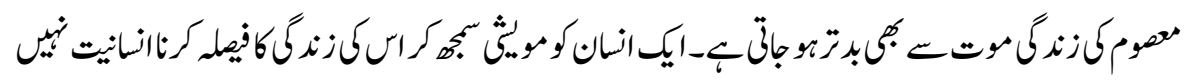

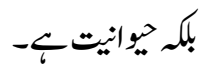

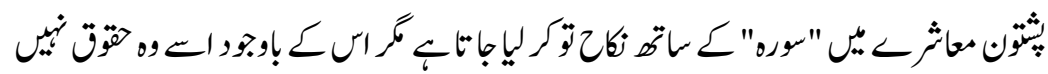

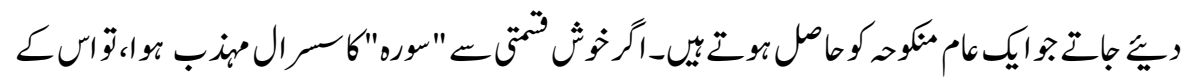

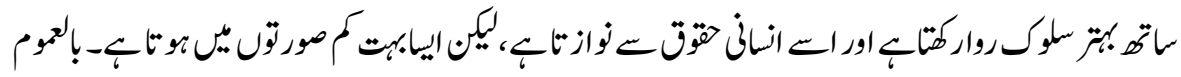

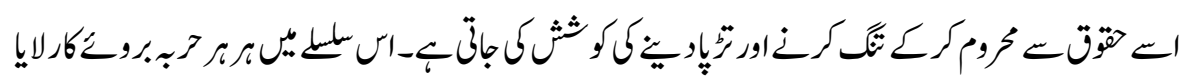

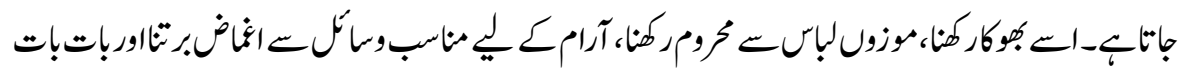

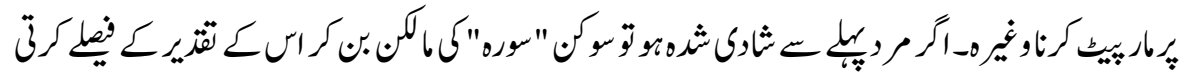

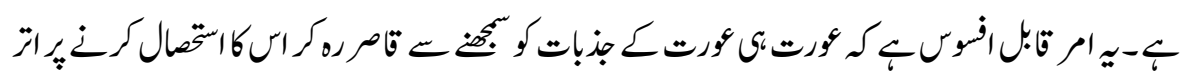

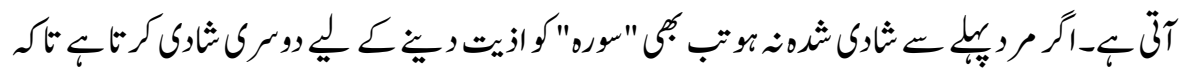

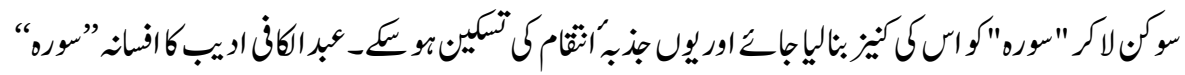

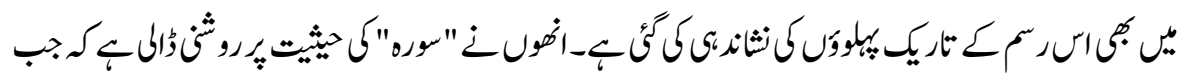

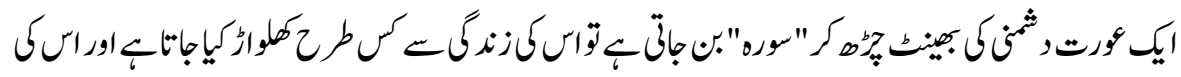

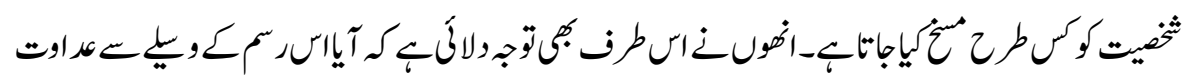

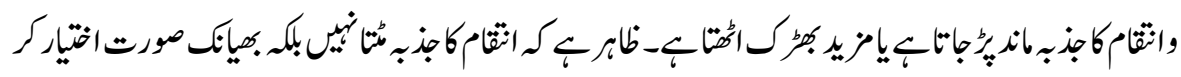

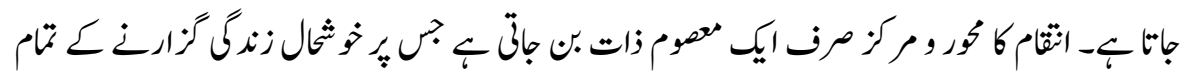

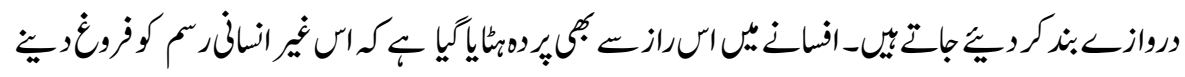

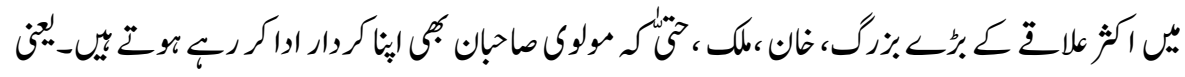

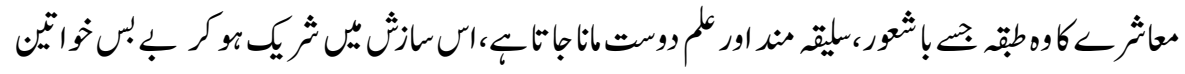

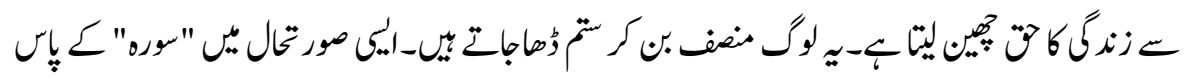

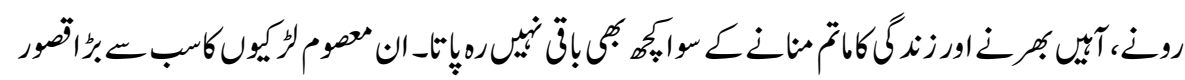

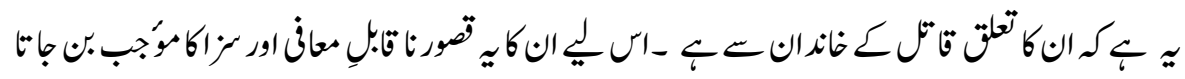




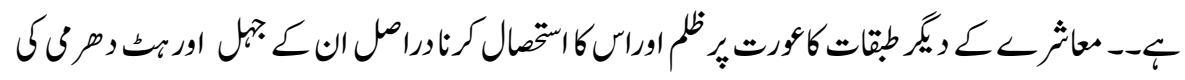

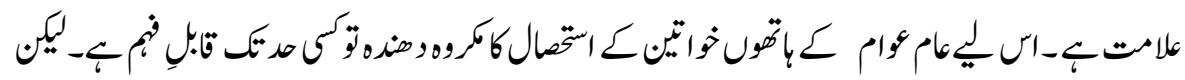

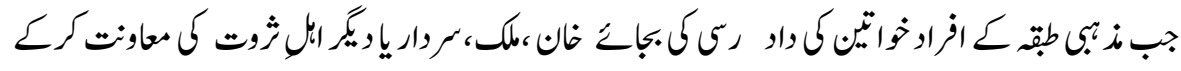

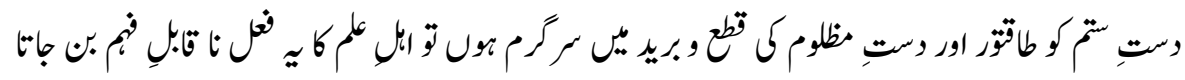

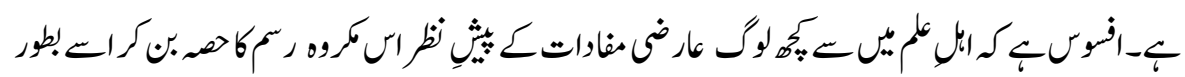

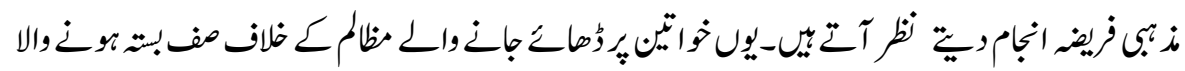

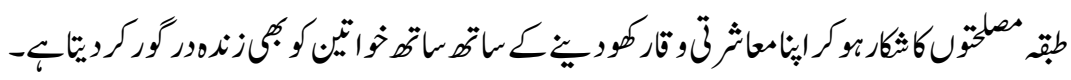

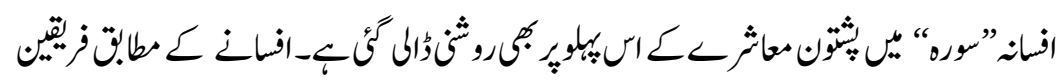

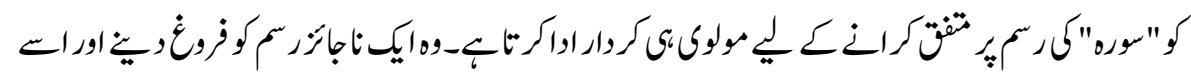

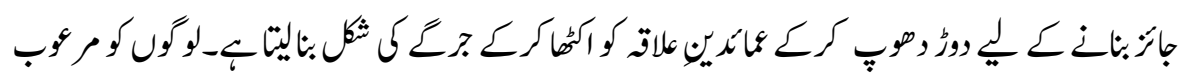

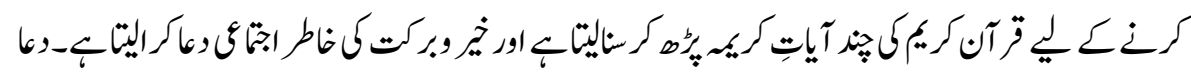

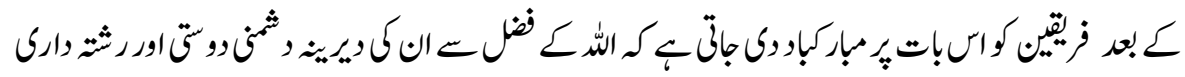

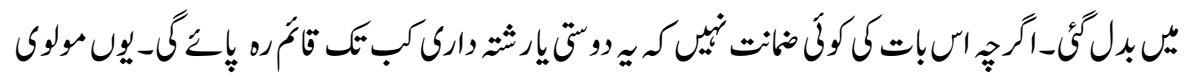

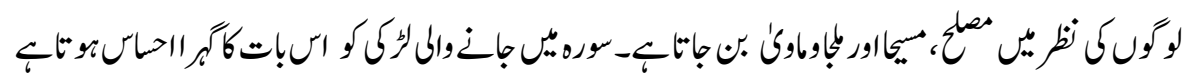

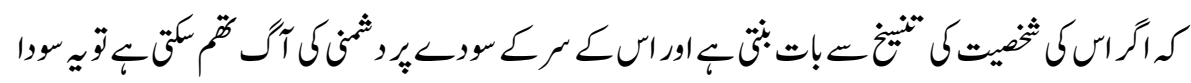

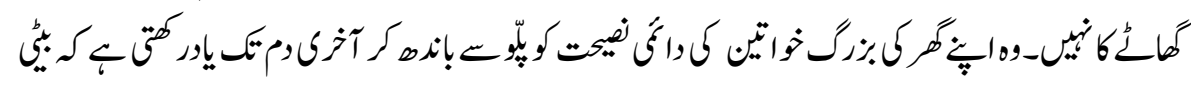

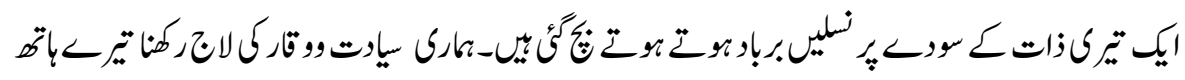

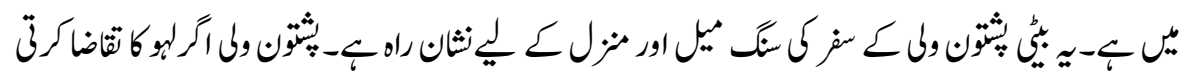

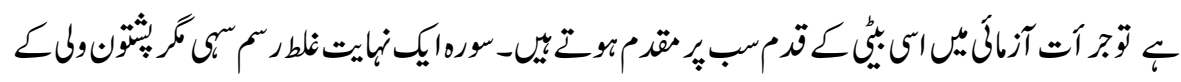

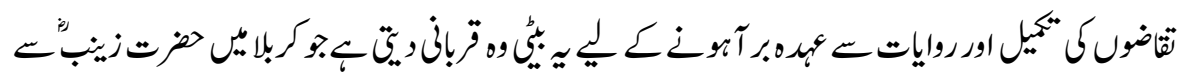

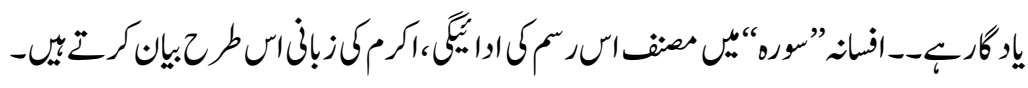

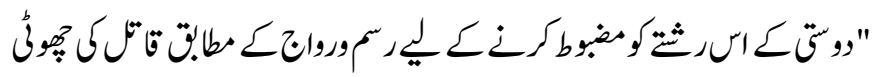

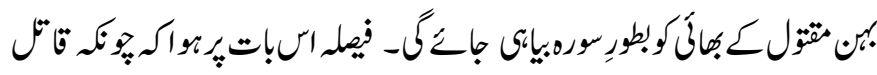




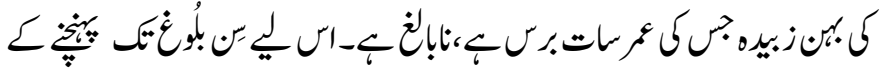

$$
\begin{aligned}
& \text { لِ } \\
& \text { (r)" }
\end{aligned}
$$

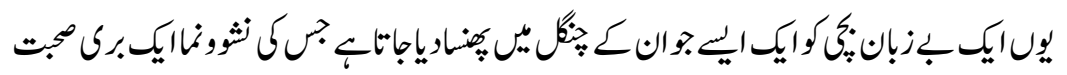

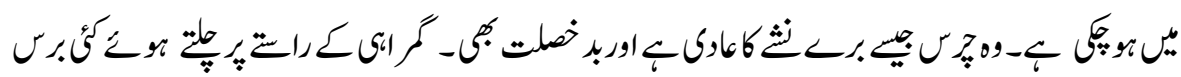

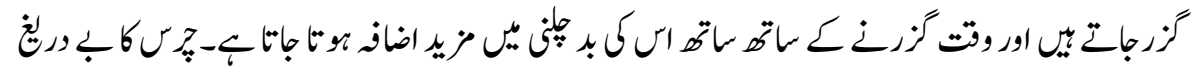

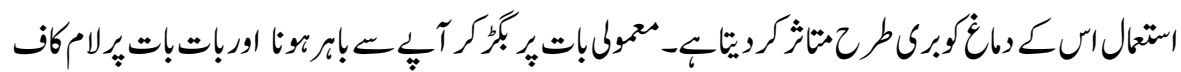

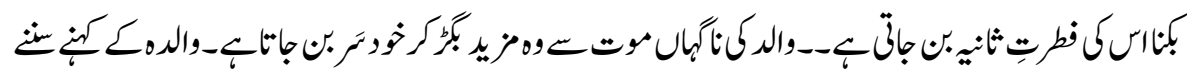

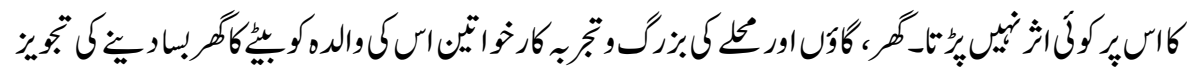

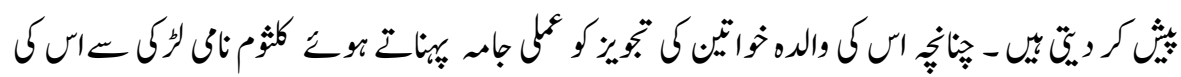

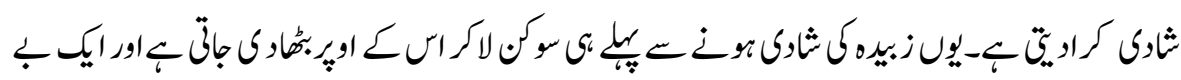

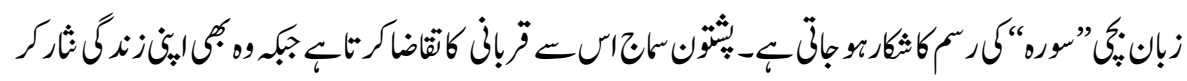

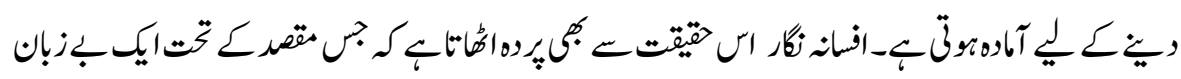

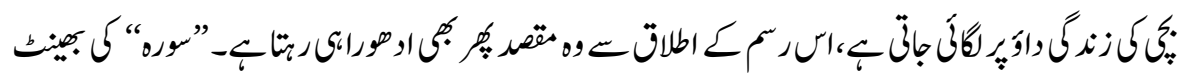

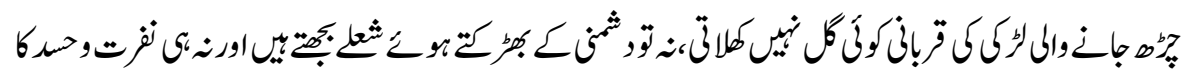

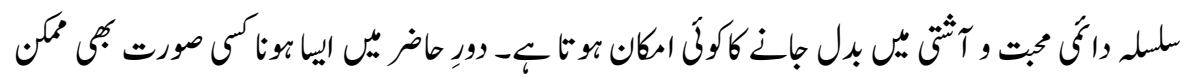

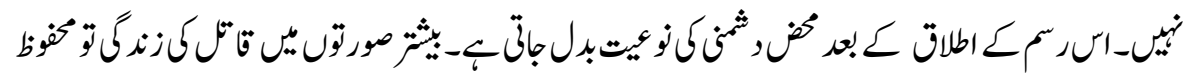

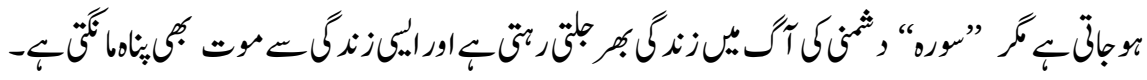

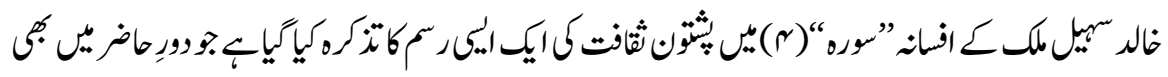

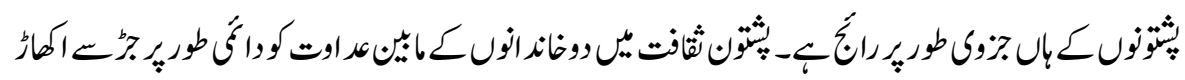

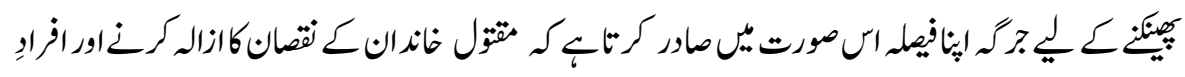

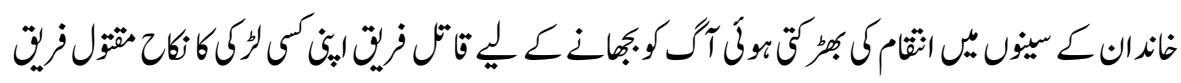

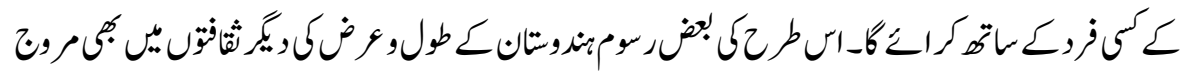




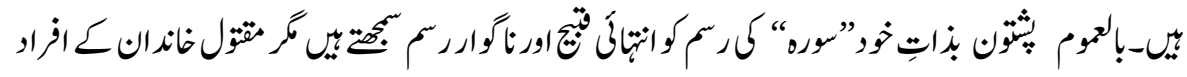

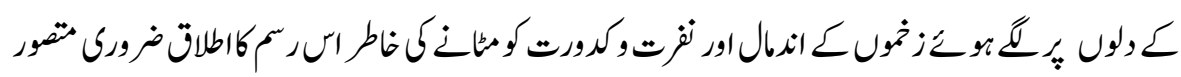

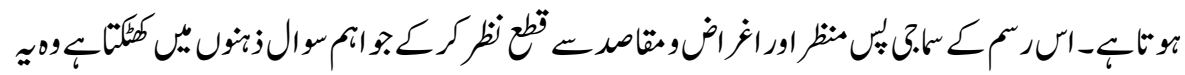

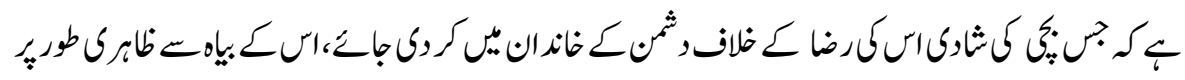

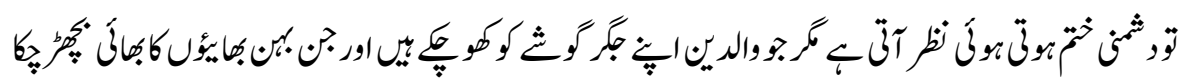

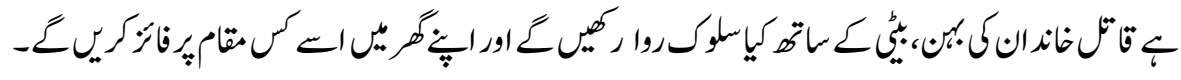

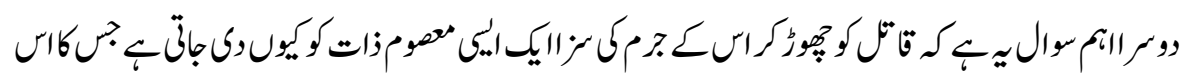

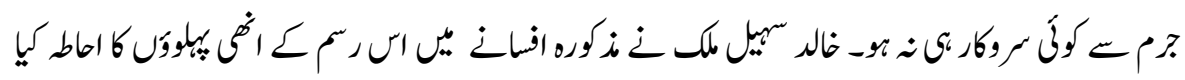

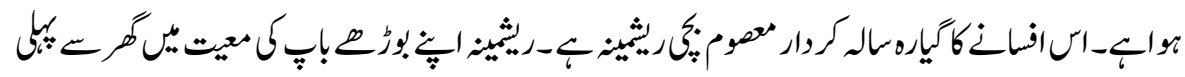

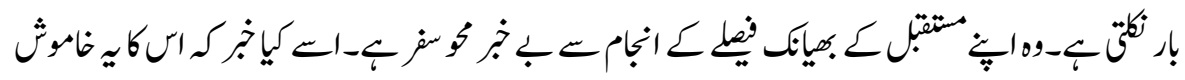

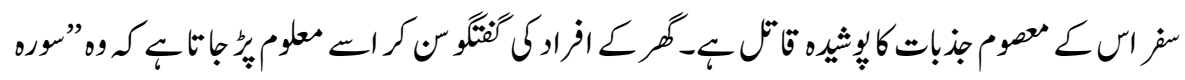

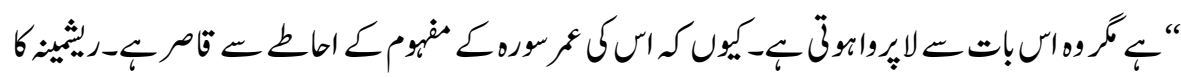

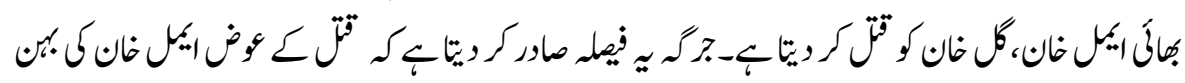

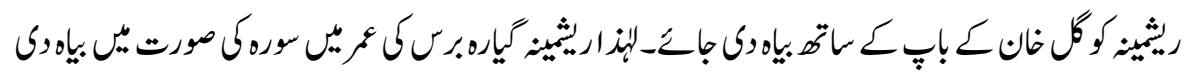

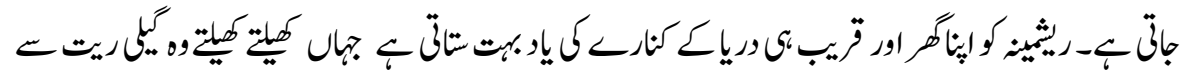

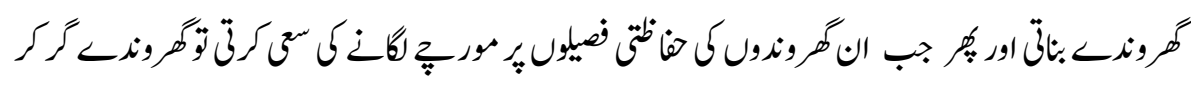

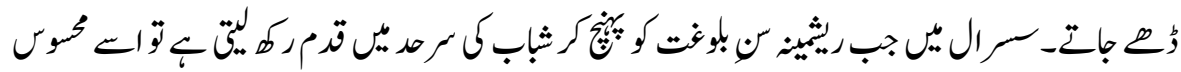

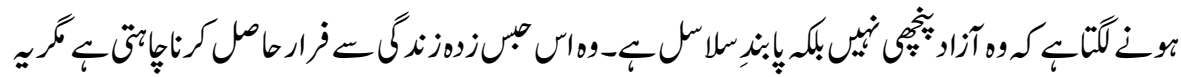

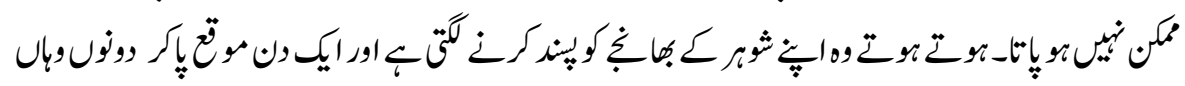

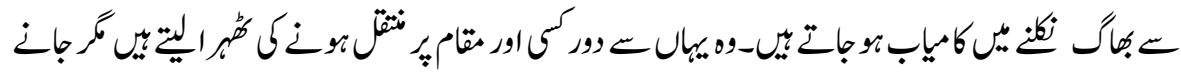

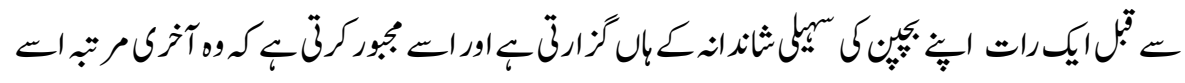

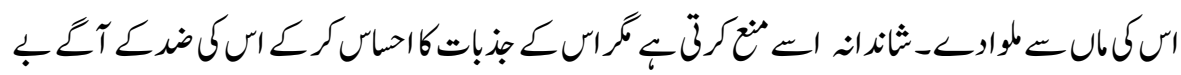

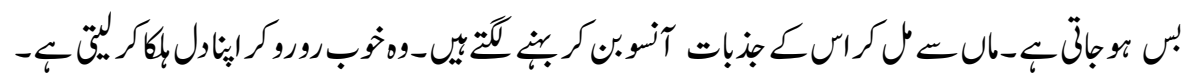




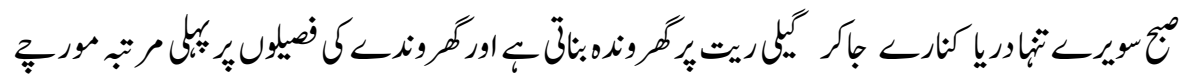

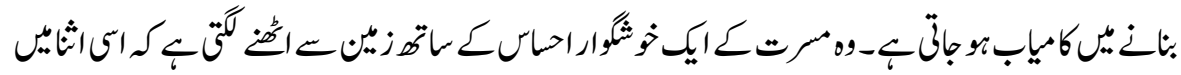

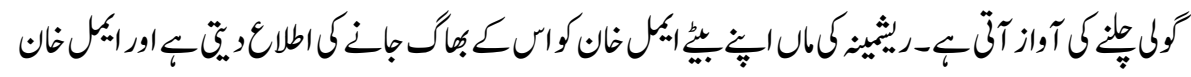

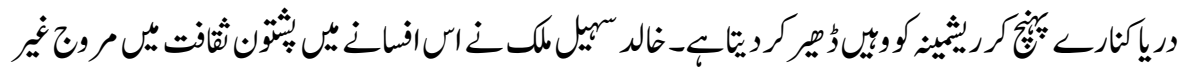

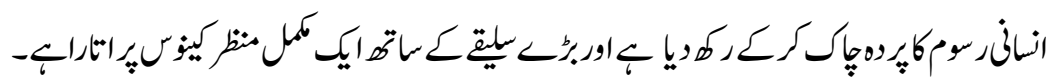

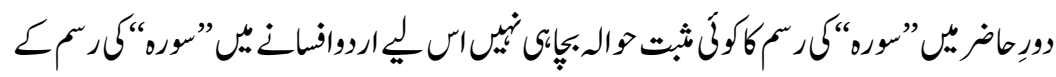

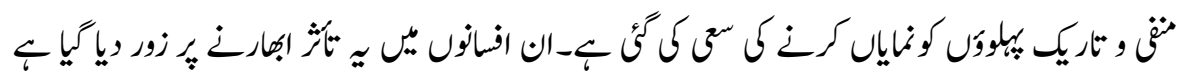

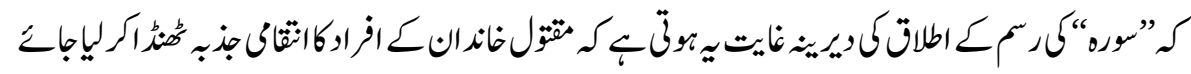

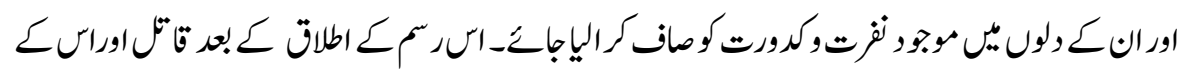

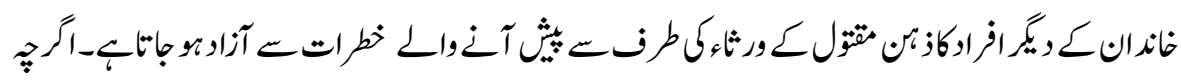

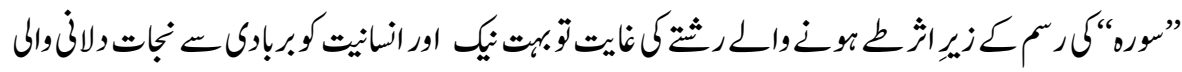

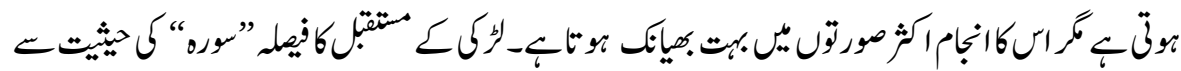

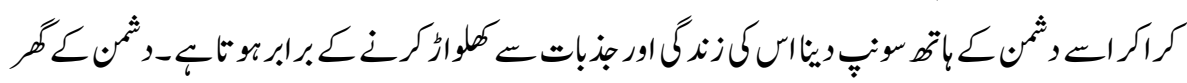

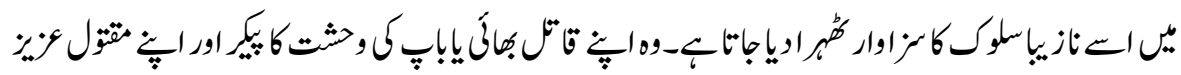

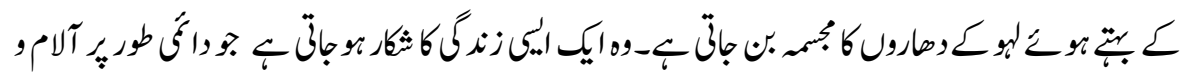

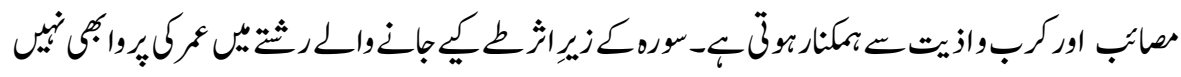

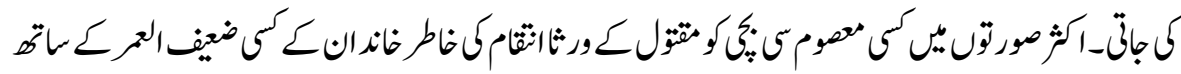

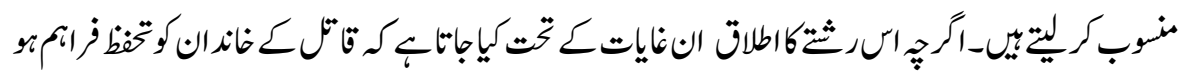

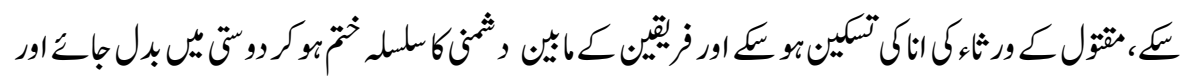

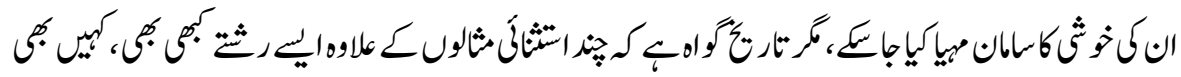

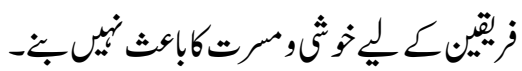




\section{والـجات}

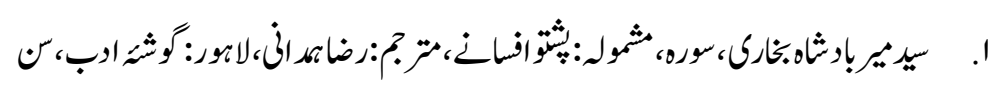

$$
\text { ندارو، }
$$

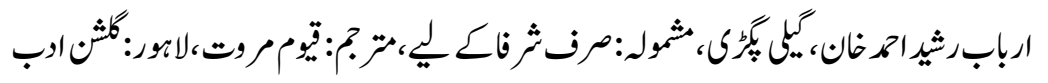

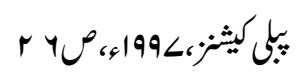

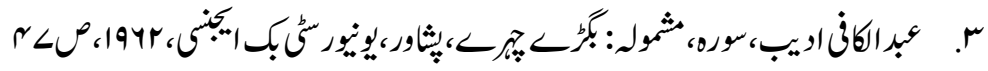

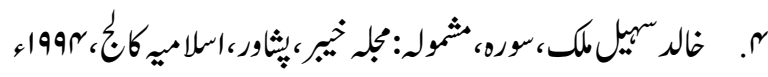

